\title{
Praças, Parques e Avenidas: áreas verdes e sua importância como espaço de lazer em Pelotas
}

Squares, Parks and Avenues: green areas and its importance as recreational spaces in Pelotas

\author{
Cláudia Werner Flach e Maiara Moreira Berdete
}

Universidade Federal de Pelotas, Pelotas, RS, Brasil

\begin{abstract}
Resumo
O presente artigo teve como objetivo ressaltar a importância das áreas verdes enquanto espaço destinado ao lazer. Foram escolhidas 5 áreas centrais de Pelotas, levando em consideração sua importância histórica e cultural: Praça Coronel Pedro Osório, Praça Piratinino de Almeida, Praça Cipriano Barcelos, Parque Dom Antônio Zattera e Parque Linear Bairro Fragata. Questionários semi estruturados foram aplicados com 72 pessoas presentes nesses parques e praças para averiguar a opinião da população no que diz respeito às condições das áreas verdes, levandose em consideração aspectos referentes a infraestrutura, vegetação, segurança, enfim condições adequadas para o lazer e a prática de atividades físicas. Foram abordadas questões presentes na legislação municipal sobre áreas verdes e arborização urbana, bem como aspectos históricos do surgimento e evolução destes locais.

Palavras-chave: Áreas verdes. Lazer. Legislação municipal.
\end{abstract}

\begin{abstract}
This article is intended to highlight the importance of green areas as spaces destined for leisure. Five different central areas in Pelotas were chosen, considering their historical and cultural relevance: Coronel Pedro Osório Square, Piratinino de Almeida Square, Cipriano Barcelos Square, Dom Antônio Zattera Park and the Linear Park Bairro Fragata. A semi-structured survey was applied to 72 present subjects at these parks and squares, in order to verify the citizens opinion over green areas. The questions considered aspects of infrastructure, vegetation, safety and proper conditions to recreation and sports practice. Topics concerned in the municipal legislation about green areas, urban afforestation, and also historical aspects of the appearance and development of those places were also approached in the questionnaire.
\end{abstract}

Keywords: Green areas. Leisure. Municipal legislation. 


\section{Introdução}

Parques, praças e avenidas fazem parte do cenário da maioria das cidades brasileiras, constituindo importantes áreas para o lazer da população, além da sua importância paisagística, cultural e ambiental. A presença significativa da população nesses espaços, principalmente nos finais de semana e nas primeiras horas da manhã e durante o entardecer reforça a importância de grandes áreas verdes urbanas destinadas à prática de esportes e atividades físicas, diversão (playground, pistas de skate, palcos para shows artísticos e culturais), enfim, para interação e convívio social.

Para o Ministério do Meio Ambiente (2014), as áreas verdes urbanas representam "o conjunto de áreas intra urbanas que apresentam cobertura vegetal, arbórea (nativa ou introduzida), arbustiva ou rasteira (gramíneas) e que contribuem de modo significativo para a qualidade de vida e o equilíbrio ambiental nas cidades". Nucci (2008) ressalta que a cobertura vegetal é um atributo muito importante para o desenvolvimento das cidades, contribuindo para a fixação dos solos, infiltração das águas pluviais, redução da poeira em suspensão, valorização visual ornamental, entre outros. A presença dessas áreas fornece para a população a possibilidade de momentos de lazer, com diferentes opções de recreação ao ar livre.

Nesse sentido, Cunha (2003) destaca que o crescimento das cidades torna cada vez mais necessário a existência e criação de espaços públicos, pois agregam qualidade ao ambiente urbano, favorecendo as condições de funcionalidade, salubridade e sociabilidade. Silva e Versiani (2011) complementam que a maioria das cidades não apresentam locais públicos suficientes para o lazer e que além da falta desses locais, há também falta de manutenção e conservação, dificultando o uso. Outro aspecto que merece ser ressaltado é a má distribuição desses locais nos diferentes bairros das cidades.

Na cidade de Pelotas, a preocupação com espaços públicos destinados ao lazer da população remota ao século XIX, quando o traçado das principais praças da cidade já estava reservado nos loteamentos. Importantes charqueadores da época consideravam fundamental a existência de praças e parques para o lazer de suas famílias, pois esses espaços representavam progresso e cultura. Mais tarde, essas praças serviram também para o abastecimento público de água, por meio de chafarizes importados da França e da grande Caixa d'Água em ferro fundido importada da Escócia. Já no início do século $\mathrm{XX}$, as praças do centro da cidade passaram por importantes etapas de modernização, jardinagem e arborização, financiadas pelas famílias mais prósperas da cidade. A vegetação das praças era composta predominantemente por plantas exóticas, muitas das quais oriundas da Europa. O cuidado com as praças era tanto que o Intendente Cipriano Barcelos legou em seu testamento uma quantia em dinheiro destinada a compra de roseiras de origem francesa para enfeitar os canteiros da Praça Coronel Pedro Osório (PARADEDA, 2003; XAVIER, 2006).

À época (final do século XIX e início do século XX), imperavam nas praças o estilo e bom gosto das requintadas famílias pelotenses. Então porque essas mesmas praças do centro da cidade são alvo de descaso atualmente? Outrora eram consideradas as mais belas do Estado, nos dias de hoje são vítimas de vândalos, de algumas pessoas que deixam seu lixo espalhado pelos canteiros e caminhos, da falta de manutenção e revitalização.

Tendo em vista o contraste das condições desses locais em épocas passadas e atuais e a importância das áreas verdes no contexto urbano, o presente artigo teve como objetivo destacar sua necessidade enquanto área de lazer para a população, atentando para as condições infraestruturais e paisagísticas. Nesse trabalho, foi levado em consideração que:

- o Ministério do Meio Ambiente e o III Plano Diretor de Pelotas (2008) englobam praças, parques e canteiros centrais ao longo de avenidas como áreas verdes;

- parque urbano é uma área verde de função ecológica, estética e de lazer com dimensão territorial maior que uma praça ou jardim público e praça é uma área verde destinada principalmente ao lazer (LIMA et al, 1994).

Foram selecionadas três praças, um parque e uma avenida na cidade de Pelotas: Praça Coronel Pedro Osório (PCPO); Praça Piratinino de Almeida (PPA); Praça Cipriano Barcelos (PCB); Parque Dom Antônio Zattera (PDAZ); e Parque Linear Bairro Fragata ao longo da Avenida Duque de Caxias (PLBF). A PCPO, PPA, PCB e PDAZ já existiam no século XIX, porém com outros nomes oficiais, que foram sendo trocados ao longo da história.

\section{Procedimentos Metodológicos}

A escolha das áreas verdes ocorreu devido a importância histórica desses locais para a cidade e para a população pelotense, por serem áreas centrais e muito frequentadas, principalmente nos finais de semana.

O levantamento de material bibliográfico para a realização da pesquisa se concentrou na busca por trabalhos referentes às áreas verdes, espaços de lazer e paisagem urbana. Deu-se uma maior atenção para documentos como a Agenda 21 de Pelotas (2004) e o III Plano Diretor Municipal de Pelotas (2008) por serem os trabalhos mais recentes e mais abrangentes, no âmbito municipal, que instituíam ações, estratégias e regulamentação para o desenvolvimento e conservação das áreas verdes e espaços públicos. Julgou-se pertinente também averiguar a evolução da legislação municipal referente às áreas verdes, compreendendo o período entre os anos 1948 e 2015. Nesse período, foram consultadas as seguintes Leis: № 1672/1968, № 2565/1980, № 3174/1988, № 4125/1996, № 4146/1996, № 4147/1996, 
№ 4594/2000, № 4724/2001, № 5880/2012, № 5910/2012 e № 6116/2014. Esse material utilizado esta disponível do site oficial da Prefeitura Municipal de Pelotas: http:// www.pelotas.com.br/.

Para a aquisição de dados concretos capazes de fornecer informações qualitativas e quantitativas e reforçar as observações de campo, foram elaborados questionários semi estruturados para verificar as condições paisagísticas e infraestruturais, diagnosticar a faixa etária, a frequência de utilização e as atividades mais exercidas nesses locais, com questões como: o que você acha da área verde com relação a vegetação, jardins, gramado (ótima, boa, regular, ruim ou péssima); o que você acha da infraestrutura - bancos, iluminação, pavimentação (ótima, boa, regular, ruim ou péssima); e quais as críticas e sugestões de melhoria para as áreas verdes. Os questionários foram aplicados com 72 pessoas que no momento da entrevista estavam frequentando as áreas verdes selecionadas (ao longo da semana e no final de semana, em novembro de 2014). Procedeu-se também a observação dos locais, que permitiu identificar alguns aspectos da infraestrura presente, como a presença/ ausência de bancos, lixeiras, banheiros públicos, playground, além das condições dos jardins e gramados. Para melhor visualização dos dados coletados, foram elaboradas tabelas.

\section{Legislação Municipal e Áreas Verdes}

Considerando de fundamental importância verificar o contexto histórico da legislação municipal no que tange a áreas verdes e arborização urbana, foram consultadas as leis disponíveis no site da Prefeitura Municipal de Pelotas compreendendo o período de 1948 a 2015.

O município, até o presente momento, teve três planos diretores, sendo o primeiro aprovado pela Lei № 1672/1968, o segundo pela Lei № 2565/1980 e o terceiro e vigente atualmente pela Lei № 5502/2008. Entretanto, é apenas no II Plano Diretor de Pelotas que as áreas verdes e a arborização urbana aparecem na legislação municipal.

\section{Plano Diretor de Pelotas (1980) e Lei № 3174 de 1988}

No presente plano, o Art. 17 estabelece que as áreas verdes que compreendem os parques naturais, as praças e os recantos destinados ao lazer são Zonas de Preservação Permanente Ecológica, ou seja, nesses locais é permitido o uso para o lazer e para fins científicos, desde que as características ambientais não sejam prejudicadas.

O Art. 32 prevê que os loteamentos devem destinar áreas para a circulação de pessoas e implantação de equipamento comunitário urbano, bem como espaços de uso público, sendo reservados $15 \%$ da área a parcelar para áreas verdes de uso público e $5 \%$ da área a parcelar para uso comunitário. E o Art. 33 incumbe ao proprietário à arborização das vias públicas, das praças e parques e das áreas de uso institucional, além da pavimentação dos passeios dessas áreas e instalação de no mínimo três equipamentos para diferentes modalidades esportivas.

O Art. 32 da Lei № 2565/1980, foi alterado pela Lei № 3174/1988, passando a ter a seguinte redação: 5\% da área a parcelar destinada aos espaços de uso público de lazer ativo; $5 \%$ para espaços de uso público destinados a áreas verdes arborizadas; 5\% para espaços de uso público de arborização dos passeios; e 3\% para área de uso institucional.

\section{Leis № 4125, № 4146 e № 4147 de 1996 e Lei № 4724 de 2001}

Em 1996, a Lei № 4125 entra em vigor, criando o "Programa Adote uma Área Verde". O Art. 1 estabelece que: Toda área verde é bem de uso comum do povo, essencial à sadia qualidade de vida, incumbindo a coletividade e ao Poder Público protegê-las, nos termos desta Lei e das demais disposições legais vigentes. O objetivo do programa era proporcionar a melhoria e angariar recursos para a manutenção e expansão das áreas verdes municipais, ou seja, todas as áreas destinadas para o lazer, descanso, prática de esportes e preservação/conservação ambiental, de uso da coletividade. A manutenção das áreas plantadas e os serviços gerais necessários seriam de responsabilidade de quem adotou a área verde. Importante ressaltar no Art. 14 que - A adoção não gera, para o adotante, qualquer direito de exploração comercial da área verde, nem altera a natureza de uso e gozo do bem público. Algumas alterações foram realizadas pela Lei № 4146/1996 (permitindo a adubação inorgânica - anteriormente não permitida - quando comprovada por profissionais habilitados a necessidade de adubação complementar) e pela Lei № 4147/1996 (que determina que a participação de pessoa física e/ou jurídica no programa não a isentará do cumprimento da legislação ambiental vigente). Em 2001, a Lei № 4724, vigente atualmente, revoga as demais leis referentes ao programa, estabelecendo que:

Art. 1 Toda área verde de domínio público é bem de uso comum do povo, essencial à sadia qualidade de vida, incumbindo à coletividade e ao Poder Público protegê-las, nos termos desta lei e das demais disposições legais.

Art. 2 Considera-se área verde, para os fins previstos nesta lei, todas aquelas públicas que são ou que estão destinadas à utilização da coletividade para lazer, descanso, prática de esportes, preservação ou conservação ambiental, bem como qualquer outro que vise à melhoria da qualidade de vida.

Art. 3 Fica instituído o "Programa Adote uma Área Verde", com o objetivo de proporcionar a melhoria para a admi- 
nistração, fiscalização, pesquisa, visitação, manutenção, implementação e expansão das áreas verdes municipais, bem como para qualquer atividade de educação ambiental nestas áreas.

Art. 4 As áreas verdes somente poderão ser adotadas, conforme o estabelecido por esta lei, mediante Tempo de Adoção de Área Verde - TAV expedido pela Secretaria Municipal de Qualidade Ambiental - SMQA, via processo contendo Plano de Adoção de Área Verde - PAV previamente analisado pelo Conselho Municipal de Proteção Ambiental - COMPAM.

Art. 10 A adoção não gera, para o adotante, qualquer direito de exploração comercial da área verde, nem altera a natureza de uso e gozo do bem público.

Art. 11 Passa a fazer parte do logradouro público municipal toda a benfeitoria realizada na área verde, não gerando qualquer tipo de ressarcimento das despesas realizadas pelo adotante.

\section{Código do Meio Ambiente do Município de Pelotas}

Em 2000, é instituído o Código do Meio Ambiente do Município de Pelotas, através da Lei № 4594, considerando todas as áreas verdes nativas, praças, parques, jardins, unidades de conservação e reservas ecológicas municipais como patrimônio público inalienável, destinadas a proteção do ecossistema, a educação ambiental, a pesquisa científica e a recreação. A responsabilidade do município para com estas áreas diz respeito manutenção e expansão da arborização. As áreas verdes nativas são consideradas Áreas de Preservação Permanente.

Incentivando a preservação das áreas verdes especiais (em imóveis particulares), os proprietários dessas áreas receberão isenção do IPTU ou redução proporcional ao índice de área verde existente no imóvel.

\section{Agenda 21 de Pelotas}

A Agenda 21 de Pelotas começou a ser elaborada em 2001, por uma comissão especial criada pela resolução 001/2001 do COMPAM. Foram realizadas Audiências Públicas para identificar as questões prioritárias para o desenvolvimento de uma cidade mais sustentável. $\mathrm{Na}$ consulta popular, participaram 2536 pessoas, que votaram prioridades gerais, elegendo:

a) No âmbito social geral: $5^{\circ}$ prioridade - promover atividades de esporte e lazer, proporcionando qualidade de vida.

b) No âmbito político institucional geral: $2^{2}$ prioridade - reforçar a campanha pelo ICMS Ecológico, criando Unidades de Conservação em Pelotas.

Para as questões abertas, a população determinou as seguintes prioridades: $1^{\underline{0}}$ Saneamento; $2^{\circ}$ Geração de Emprego; 3o Áreas Verdes; $4^{\circ}$ Educação; 5o Calçamento; $6^{\circ}$ Coleta Seletiva; $7^{\circ}$ Conscientização da População; $8^{\circ}$ Combate à Miséria; $9^{\circ}$ Saúde; $10^{\circ}$ Segurança Pública; $11^{\circ}$ Limpeza da Cidade; $12^{\circ}$ Limpeza e Conservação da Praia; $13^{\circ}$ Informação à População; $14^{\circ}$ Controle de Enchentes; 15ํㅡㄹ Moradia; $16^{\circ}$ Coleta do Lixo, $17^{\circ}$ Iluminação; $18^{\circ}$ Melhoria do Transporte Público; 19oㅡㄹ Arborização; $20^{\circ}$ Controle de Zoonoses.

Com base nas prioridades definidas nas Audiências Públicas, durante a 2 ${ }^{\mathrm{a}}$ Conferência Municipal de Qualidade Ambiental, foram elaboradas ações estratégicas para atender a demanda local. No Âmbito Geoambiental, a curto prazo, surge a necessidade de aumentar a cobertura vegetal urbana através de ações entre o Poder Público e a iniciativa privada e preservar, conservar e recuperar Áreas de Preservação Permanente; a médio prazo implementar Parques Urbanos ao longo do Canal São Gonçalo, um Parque no Pontal da Barra e um Parque Urbano no banhado junto a Estação Rodoviária; e a longo prazo, implantar projetos arquitetônicos com área com cobertura vegetal. No Âmbito Político Institucional, a curto prazo, destinar recursos do orçamento público para políticas que induzam a sustentabilidade como áreas verdes e unidades de conservação, dotar o horto municipal com infraestrutura e recursos humanos para a produção de mudas destinadas a arborização; a médio prazo instituir um IPTU ecológico para incentivar o aumento da cobertura vegetal.

\section{Plano Diretor de Pelotas (2008)}

A Lei no 5.502/2008 Institui o III Plano Diretor Municipal, estabelecendo diretrizes e proposições para o ordenamento e desenvolvimento territorial no Município de Pelotas. No Art. 144 da presente lei, fica estabelecido que: $\S 1^{\circ}$. Toda área de praça, canteiro central de avenidas e largos passam a ser classificadas como áreas verdes e, consequentemente, todo uso comercial fixo passa a ser proibido. Também estão estabelecidas as Áreas Especiais de Interesse do Ambiente Cultural (AEIAC - Art. 70) e Áreas Especiais de Interesse Cultural pelos Focos Especiais de Interesse Cultural (FEIC - Art. 71).

\section{Lei № 5880 e № 5910 de 2012}

Complementando o Código do Meio Ambiente de Pelotas no que se refere a arborização, em 2012 entra em vigor a Lei № 5880, incentivando a arborização de ruas, praças e jardins, cabendo ao Executivo Municipal o fornecimento gratuito de mudas de árvores nativas e plantas ornamentais aos munícipes interessados; e a Lei № 5910, instituindo o "Prêmio Primavera", a ser conferido aos munícipes e entidades do setor público ou privado, destaques na conservação e manutenção de praças, canteiros e rotatórias do município. 


\section{Lei № 6116 de 2014}

E por fim, em 2014, conferindo um pequeno passo em relação a acessibilidade em áreas públicas destinadas ao lazer ou recreação, a Lei № 6116, determina a instalação de no mínimo, 01 brinquedo adaptado para crianças com deficiência ou com mobilidade reduzida. Esses brinquedos adaptados serão instalados gradativamente nas praças e parques.

\section{4 Áreas de Estudo - Contexto Histórico}

No auge do desenvolvimento de Pelotas no século XIX, ricos charqueadores patrocinavam o processo de urbanização da cidade, pois queriam torná-la um centro reconhecido pelo bom gosto e cultura. Importavam produtos industrializados de países desenvolvidos, que eram reconhecidos pela qualidade e refinamento. Nesse sentido, as praças começaram a ganhar destaque, recebendo chafarizes (símbolo de progresso), pois era o que havia de mais moderno na Europa referente ao abastecimento de água. Assim, ostentava-se riqueza e bom gosto em locais públicos, onde qualquer viajante que chegasse na cidade perceberia o quão importante eram as tradicionais famílias pelotenses. A vegetação das praças também era alvo dessa ostentação. Grande parte da arborização era constituída por plantas exóticas e os jardins recebiam inúmeras roseiras francesas, além dos canteiros, projetados por importantes jardineiros estrangeiros. (XAVIER, 2006).

Devido ao destaque dado as áreas verdes e sua importância para a população no século XIX e meados do século $X X$, e a situação contrastante em que se encontram esses locais atualmente, julgou-se pertinente compreender o que a população pensa sobre as condições desses locais e o que contribui para sua precariedade, bem como alternativas para tornar as praças mais atraentes novamente.

Como destacado anteriormente, para este estudo foram escolhidas as seguintes áreas verdes urbanas de Pelotas: Praça Coronel Pedro Osório (PCPO), Praça Piratinino de Almeida (PPA), Praça Cipriano Barcelos (PCB), Parque Dom Antônio Zattera (PDAZ) e Parque Linear Bairro Fragata (PLBF) - canteiro central da Avenida Duque de Caxias. A seguir estão descritas algumas características desses locais e a distribuição espacial das áreas de estudo está representada na Figura1.

\section{Praça Coronel Pedro Osório}

Núcleo do Segundo Loteamento de Pelotas, a praça possui caráter histórico-cultural e no seu entorno encontram-se os principais prédios históricos tombados da cidade. Essa praça esta localizada na parte central da cidade de Pelotas, com uma área de $19.500 \mathrm{~m}^{2}$.
Em 1829, o terreno onde hoje se situa a praça já havia sido reservado para este fim, porém ainda não apresentava a configuração de um espaço destinado ao lazer. No centro desse terreno foi instalado um Pelourinho, onde criminosos e delinquentes eram amarrados e castigados publicamente. É a partir de 1870 que a praça começa a ganhar forma. (PARADEDA, 2003).

Em 1873, a Companhia Hydráulica Pelotense, instalou o primeiro chafariz de Pelotas com a função de abastecer de água a população, na então chamada Praça Pedro II. Esse chafariz foi fabricado pela Fundição Durenne, localizada no departamento de Haute-Marne, na região da Champagne Ardenne, na França. Atualmente, o chafariz é conhecido como Fonte das Nereidas e é uma réplica do Chafariz Ross Fountain, de Edimburgo, na Escócia. Em 1877 , a praça foi considerada a mais ampla e elegante da Província e nesse mesmo ano foi suspenso o fornecimento de água através do chafariz. A praça começava então a se configurar como local de passeio e lazer para as abastadas famílias pelotenses. (XAVIER, 2006).

Segundo Santos (2012), em 1876 deu-se início ao processo de arborização da praça, e em 1877 de ajardinamento. No ano seguinte o local recebeu iluminação e em 1879 foi instalado um lago habitado por diversos tipos de peixes.

Em 1914, a praça passa por uma grande reforma, com o remodelamento de seus canteiros e nova arborização, sendo a antiga totalmente substituída. (PARADEDA, 2003).

\section{Praça Piratinino de Almeida}

Esta praça também é uma referência cultural pela presença da Caixa d'Água, tombada em nível federal, e pelo prédio da Santa Casa de Misericórdia. Também localizada na parte central da cidade, possui uma área de $10.500 \mathrm{~m}^{2}$.

O terreno destinado à praça já estava no traçado da cidade desde 1815. Inicialmente recebeu o nome de Praça da Caridade, pois esta situada em frente a Santa Casa de Misericórdia de Pelotas. Segundo Paradeda (2003), essa praça foi um dos principais espaços públicos do século XIX, servindo de largo ou ante-sala da Santa Casa.

Em 1875, devido a necessidade de abastecimento de água, foi instalada a Caixa d'Água. O material para sua construção foi trazido de Paisley, Escócia. Feita em ferro fundido, é um dos principais elementos da riqueza de Pelotas do século XIX. (XAVIER, 2006).

\section{Praça Cipriano Barcelos}

Outra praça localizada no centro de Pelotas, a Praça Cipriano Barcelos tem uma área de $13.750 \mathrm{~m}^{2}$. Em seu passado recente, o leito do Arroio Santa Bárbara passava no local, até ser canalizado. A ponte tombada sob a qual passava o arroio ainda encontra-se como marco dessa época. 


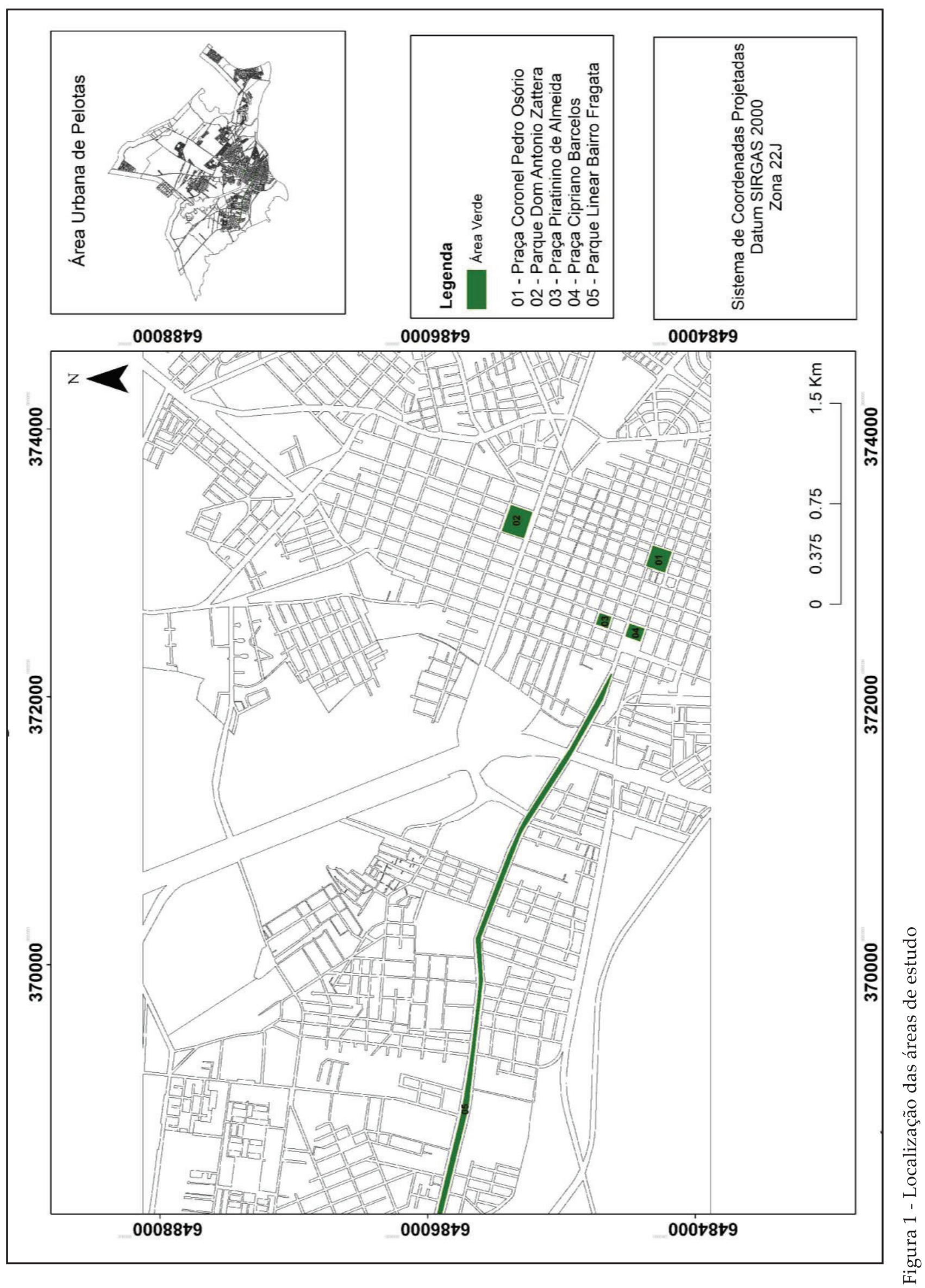


Ao longo de sua história, teve outros nomes oficiais, como Praça Dom Pedro II e Praça da Constituição. Popularmente é conhecida como Praça dos Enforcados, pois em 1850 foi instalada uma forca no local, transferida do atual Parque Dom Antônio Zattera. (PARADEDA, 2003).

Em 1914, recebeu o Chafariz Santo Ignácio, inicialmente instalado em um terreno na Rua São Miguel (atual Quinze de Novembro), esquina com a Rua Santo Ignácio (atual Gomes Carneiro), em 1876. Popularmente é conhecido como Chafariz dos Cupidos. (XAVIER, 2006).

Peter (2004) destaca que a primeira intervenção no leito do Arroio Santa Bárbara ocorreu ainda no século XIX, em função das melhorias na praça, sendo o leito desviado por meio de um canal e o antigo leito passou a fazer parte da praça, que passou por um processo de aterro e nivelamento em 1888. É na década de 1950, após diversas enchentes, que se desenvolvem projetos para a canalização do arroio, desviando assim, boa parte do leito.

\section{Parque Dom Antônio Zattera}

O parque apresenta grande valor histórico e cultural devido a sua utilização como parque urbano (área verde de função ecológica, estética e de lazer, maior que uma praça ou jardim público - Lima et al, 1994). É uma das maiores áreas verdes do centro de Pelotas, com $37.925 \mathrm{~m}^{2}$, destacando-se pela grande quantidade de massa verde presente no local.

Seu primeiro nome oficial foi Praça General Câmera e posteriormente Júlio de Castilho. Foi um dos locais sugeridos para a instalação de um dos chafarizes destinados ao abastecimento de água no século XIX, mas devido a sua distância do aglomerado populacional na época e por não haver nada de interessante no terreno, a proposta foi rejeitada. Relatos indicam que a partir de 1917 o local começou a receber melhorias, com iluminação e jardins e em 1924, foi instalado um kind-garden, símbolo de cultura em países abastados. A principal finalidade do parque era para a recreação das crianças. Em 1929, o lago presente no local foi aterrado. (PARADEDA, 2003).

\section{Parque Linear Bairro Fragata}

O local possui importância como conexão viária de entrada e saída do bairro Fragata. As dimensões de seu canteiro central possibilitam a sua utilização como espaço público aberto, com uma área de aproximadamente $187.390 \mathrm{~m}^{2}$.

Oliveira (2007) ressalta que inicialmente, a Avenida Duque de Caxias era uma estrada rústica, na Fazenda Santa Bárbara, feita para facilitar o escoamento de produtos provenientes das colônias. Com o tempo, foram surgindo armazéns ao longo da estrada e posteriormente as primeiras casas e vilas. A avenida recebeu muitos outros nomes em sua história: Estrada de Piratini, Estrada
Geral, Estrada do Fragata, Avenida Vinte de Setembro e posteriormente Avenida Daltro Filho até 1958. Ainda segundo a autora, por volta de 1905, Carlos Ritter plantou eucaliptos formando um corredor central na avenida. Nesse corredor funcionaram bondes de tração animal e posteriormente o bonde elétrico. Remanescentes dessa época, ainda hoje podem ser vistos dezenas desses eucaliptos.

\section{Resultados e Discussão}

O III Plano Diretor do Município de Pelotas, de 2008, prevê a proteção do ambiente natural, ampliando o sistema de áreas verdes do município, pois estas áreas se constituem como elementos integradores da paisagem urbana. Também estão estabelecidas as Áreas Especiais de Interesse do Ambiente Cultural (AEIAC - Art. 70) e Áreas Especiais de Interesse Cultural pelos Focos Especiais de Interesse Cultural (FEIC - Art. 71). Para as áreas que correspondem ao VI - AEIAC (Parque Linear Bairro Fragata), II - FEIC (Praça Coronel Pedro Osório), IV - FEIC (Praça Cipriano Barcellos), VI - FEIC (Praça Piratinino de Almeida) e VIII - FEIC (Parque Dom Antônio Zattera), objetos deste estudo, foram previstas ações referentes a projetos paisagísticos, instalação de mobiliário e equipamentos urbanos, melhorias na vegetação, enfim, condições para a permanência e conforto da população, valorizando seu caráter histórico, cultural e ambiental.

Tendo como base todas as informações obtidas na revisão bibliográfica e legislação do município referente às áreas verdes, foram coletados dados através de questionários semi estruturados nos 5 locais alvos deste estudo. Com base nesses dados, foi possível constatar que há um consenso geral da população com relação às condições infraestruturais. As tabelas 1, 2, 3 e 4 sintetizam as informações adquiridas. Na tabela 1 fica evidente que as 5 áreas verdes apresentam praticamente os mesmos problemas. A falta de infraestrutura básica como lixeiras e iluminação são algumas das muitas reclamações dos frequentadores. A insegurança, principalmente a noite também é um item bastante destacado. Entretanto, na PPA e PCB até mesmo durante o dia a população fica receosa em frequentar esses locais. As más condições da pavimentação, dos bancos, playgrounds e banheiros é outro fator determinante para o desgosto dos entrevistados.

Na tabela 2, é possível observar que iluminação, pavimentação e bancos são itens presentes em todas as áreas verdes pesquisadas, o que não garante as boas condições dos mesmos. Já os banheiros estão presentes apenas na PCPO e PDAZ e a PPA não conta com playground. Fontes e/ou lagos não existem atualmente na PPA, PDAZ e PLBF e lixeiras também não são encontradas na PPA e PCB.

Através da tabela 3 verificamos que $66 \%$ dos entrevis- 
Tabela 1 - Principais problemas relatados nas áreas de estudo

\begin{tabular}{|c|c|}
\hline Local & Principais Problemas Relatados \\
\hline $\begin{array}{l}\text { Praça Coronel Pedro Osório } \\
\text { (PCPO) }\end{array}$ & $\begin{array}{l}\text { Sujeira nos banheiros; insuficiência de iluminação, segurança e } \\
\text { lixeiras; falta de manutenção. }\end{array}$ \\
\hline $\begin{array}{l}\text { Praça Piratinino de Almeida } \\
\text { (PPA) }\end{array}$ & $\begin{array}{l}\text { Falta de lixeiras e playground; iluminação precária; insegurança; } \\
\text { pavimentação e bancos em más condições; falta de manutenção. }\end{array}$ \\
\hline Praça Cipriano Barcelos (PCB) & $\begin{array}{l}\text { Insegurança; iluminação e quantidade de bancos e lixeiras } \\
\text { insuficientes; falta de banheiros; playground em condições } \\
\text { precárias; falta de manutenção. }\end{array}$ \\
\hline $\begin{array}{l}\text { Parque Dom Antônio Zattera } \\
\text { (PDAZ) }\end{array}$ & $\begin{array}{l}\text { Sujeira nos banheiros; falta de iluminação, segurança e lixeiras; } \\
\text { drenagem deficiente no playground; falta de manutenção. }\end{array}$ \\
\hline $\begin{array}{l}\text { Parque Linear Bairro Fragata } \\
\text { (PLBF) }\end{array}$ & $\begin{array}{l}\text { Falta de iluminação, segurança e lixeiras; arborização em más } \\
\text { condições; falta de manutenção. }\end{array}$ \\
\hline
\end{tabular}

Tabela 2 - Infraestrutura presente nas áreas de estudo

\begin{tabular}{lccccccc}
\hline Local & Iluminação & Playground & Pavimentação & Bancos & Banheiro & Fontes/Lagos & Lixeiras \\
\hline PCPO & $\checkmark$ & $\checkmark$ & $\checkmark$ & $\checkmark$ & $\checkmark$ & $\checkmark$ & $\checkmark$ \\
\hline PPA & $\checkmark$ & $X$ & $\checkmark$ & $\checkmark$ & $X$ & X & X \\
\hline PCB & $\checkmark$ & $\checkmark$ & $\checkmark$ & $\checkmark$ & $X$ & $\checkmark$ & X \\
\hline PDAZ & $\checkmark$ & $\checkmark$ & $\checkmark$ & $\checkmark$ & $\checkmark$ & $X$ & $\checkmark$ \\
\hline PLBF & $\checkmark$ & $\checkmark$ & $\checkmark$ & $\checkmark$ & $X$ & $X$ & $\checkmark$ \\
\hline
\end{tabular}

Tabela 3 - Condições da infraestrutura e vegetação/arborização

\begin{tabular}{lccccccccccc}
\hline & & \multicolumn{3}{c}{ Infraestrutura (bancos, banheiros...) } & \multicolumn{3}{c}{ Vegetação (arborização, jardim...) } \\
Local & Amostra & Ótima & Boa & Regular & Ruim & Péssima & Ótima & Boa & Regular & Ruim & Péssima \\
\hline PCPO & 18 & - & 7 & 9 & 2 & - & 5 & 13 & - & - & - \\
\hline PPA & 8 & - & - & 1 & 5 & 2 & - & 5 & 3 & - & - \\
\hline PCB & 8 & - & - & - & 5 & 3 & - & 3 & 3 & 1 & 1 \\
\hline PDAZ & 18 & - & 9 & 8 & 1 & - & 7 & 11 & - & - & - \\
\hline PLBF & 20 & - & 8 & 3 & 3 & 6 & 1 & 9 & 7 & 2 & 1 \\
\hline Total & 72 & 0 & 24 & 21 & 16 & 11 & 13 & 41 & 13 & 3 & 2 \\
\hline
\end{tabular}

Tabela 4 - Faixa etária dos entrevistados e frequência que utilizam as áreas verdes

\begin{tabular}{|c|c|c|c|c|c|c|c|c|}
\hline \multirow[b]{2}{*}{ Local } & \multirow[b]{2}{*}{ Amostra } & \multicolumn{4}{|c|}{ Faixa Etária (anos) } & \multicolumn{3}{|c|}{ Frequenta o Local: } \\
\hline & & $\leq 20$ & $\begin{array}{c}\text { De } 21 \text { a } \\
35\end{array}$ & $\begin{array}{c}\text { De } 36 \text { a } \\
50\end{array}$ & $\geq 51$ & Frequentemente & $\begin{array}{c}\text { Finais de } \\
\text { semana }\end{array}$ & Raramente \\
\hline PCPO & 18 & 4 & 5 & 3 & 6 & 7 & 5 & 6 \\
\hline PPA & 8 & 1 & 2 & 1 & 4 & - & 1 & 7 \\
\hline PCB & 8 & 2 & 2 & 1 & 3 & 2 & - & 6 \\
\hline PDAZ & 18 & 4 & 3 & 5 & 6 & 11 & 6 & 1 \\
\hline PLBF & 20 & 3 & 5 & 5 & 7 & 10 & 5 & 5 \\
\hline Total & 72 & 14 & 17 & 15 & 26 & 30 & 17 & 25 \\
\hline
\end{tabular}


tados (48 pessoas) consideram as condições infraestruturais como regulares, ruins ou péssimas. Apenas a PPA não possui playground, não sendo encontrado nenhum registro da existência do mesmo em épocas passadas. Na PCPO e PCB, ainda estão presentes os chafarizes originalmente destinados ao abastecimento de água da população no século XIX. Na PCPO, além do chafariz, o lago remanescente do século XIX ainda esta presente e é habitado por peixes e tartarugas.

Ainda na tabela 3, percebe-se que 75\% dos entrevistados (54 pessoas) consideram a vegetação (árvores e jardins) em ótimas ou boas condições. Entretanto, em conversa com os entrevistados, surge a necessidade de melhorias na vegetação, com podas frequentes, arborização, ajardinamento e substituição de árvores que representam perigo para a população.

Com relação à faixa etária da população (Tabela 4), os índices se mantêm bem distribuídos até 50 anos. Predominam pessoas com mais de 51 anos, representando $36,11 \%$ dos entrevistados. Com relação a frequência que utilizam as áreas verdes, observa-se que na PPA e PCB, a grande maioria frequenta o local raramente, visto as condições destes locais. Nas outras áreas verdes, os entrevistados utilizam esses locais frequentemente e nos finais de semana, para diversos fins (Tabela 4).

A Praça Coronel Pedro Osório é a que apresenta melhores condições (quando comparada com as demais pesquisadas) e é bastante frequentada durante a semana e nos finais de semana para atividades físicas, descanso e diversão. Recebe diversos eventos artísticos e culturais como a Feira do Livro, Pelotas Doce Natal, Pelotas Jazz Festival, que atraem a população de diferentes áreas da cidade. Entretanto, sua infraestrutura é classificada pelos entrevistados, predominantemente, como regular e boa, pois ocorrem problemas relacionados a sujeira dos banheiros, iluminação e segurança. A faixa etária e a frequência de utilização são variadas, pois por ser uma praça central e contornada pelo centro histórico, muitas pessoas são de outras cidades e bairros.

Atualmente, a PCPO está passando por um processo de requalificação do paisagismo, com instalação de bancos, limpeza de monumentos, plantio de mudas de flores, reposição de ladrilhos do piso, reconstrução de meios fios, reposição de postes e troca de lâmpadas. Esse projeto de requalificação é financiado por recursos federais e municipais e também prevê a elaboração de um manual de procedimentos anuais de manutenção da praça.

Já as praças Piratinino de Almeida e Cipriano Barcelos são as que apresentam as condições mais precárias com infraestrutura ruim a péssima. A população que frequenta esses locais convive com a falta de manutenção da vegetação (poda, corte da grama, espécies daninhas), bem como com a inexistência de infraestrutura adequada. Através das observações, foi possível identificar a presença de bancos, pavimentação e iluminação, porém o desgaste e a insuficiência desses aparatos se destacam em meio a vegetação dessas praças. Também são as praças que geram maior insegurança na população e consequentemente as que recebem um menor número de frequentadores. Nos momentos em que foram realizadas as entrevistas, pouquíssimas pessoas estavam presentes nesses locais, sendo esse o motivo para o menor número de questionários aplicados.

O Parque Dom Antônio Zattera é o mais frequentado, especialmente nos finais de semana, por apresentar uma área relativamente grande, pista de skate, playground, frequentemente shows e atividades artísticas e culturais e também devido às feiras de artesanato que ocorrem nos domingos ao longo do canteiro central da Avenida Bento Gonçalves. O espaço para realizar atividades físicas também é um dos atrativos. Apesar da infraestrutura boa a regular, são relatados problemas de drenagem deficiente (playground), insegurança, sujeira nos banheiros e falta de manutenção. Grupos de diferentes faixas etárias frequentam o local, visando realizar atividades físicas, se divertir e descansar.

O Parque Linear Bairro Fragata ao longo da Avenida Duque de Caxias, por apresentar uma área bastante extensa no canteiro central é propício para a prática de atividades físicas. Durante a noite, os trailers móveis de lanches são um dos motivos para grande quantidade de pessoas no local. Pessoas de diferentes idades utilizam o a avenida frequentemente em busca de diversão, descanso ou atividades físicas. Apesar do fluxo bastante elevado de pessoas, também são encontrados problemas relativos a falta de manutenção, iluminação, segurança e número de lixeiras.

Ainda com relação ao PLBF, destaca-se a presença de muitos trechos que servem de estacionamento para revendedoras de automóveis, supermercados, bem como outros estabelecimentos comerciais. A presença constante dos carros nesses locais prejudica visivelmente a vegetação, sendo que em muitos trechos o solo encontra-se completamente exposto. Por apresentar uma extensão considerável, dividindo o parque em três setores, é possível destacar que a parte inicial (mais próxima ao centro de Pelotas) é a que apresenta melhores condições de uso, a parte intermediária (mais utilizada) necessita uma maior atenção do poder público e também da população, e a parte final apresenta vegetação bem estabelecida, entretanto a presença constante de lixo prejudica o local.

Visando melhorar as condições das áreas verdes e consequentemente ampliar o seu uso, sugerem-se algumas melhorias nesses locais como o aumento da arborização em determinados pontos substituindo algumas árvores que colocam em risco a segurança da população, a conscientização dos donos de cachorros com relação às fezes dos animais, instalar playgrounds e pistas para caminhada e corrida e aumentar a acessibilidade. Ainda com relação as melhorias, e levando-se em consideração as reclamações de boa parte da população entrevistada e o observado pelas autoras tanto no período de entrevista 
quanto nos dias em que esses locais são frequentados, destaca-se a necessidade evidente de aumentar a iluminação, segurança, número de lixeiras e de bancos e brinquedos nos playgrounds.

Um aspecto ressaltado por uma parcela significativa de entrevistados diz respeito a falta de educação e de cuidados de algumas pessoas para com a estrutura das praças, parques e avenidas. Segundo esses entrevistados, não adianta realizar a manutenção dos locais se a população não colaborar para manter os locais com boas condições de uso.

\section{Conclusões}

Através desse trabalho, percebe-se a urgente necessidade de melhorar as condições infraestruturais das áreas verdes de Pelotas, principalmente no quesito de iluminação e limpeza. Aumentar a segurança dos locais também é uma demanda importante, pois algumas praças deixam de ser frequentadas como espaço de lazer devido a insegurança. Visto que a cidade possui poucas áreas verdes na zona urbana, torna-se ainda mais necessário realizar periódicas manutenções nesses locais.

Quando a vegetação atual é comparada com os relatos da vegetação nos séculos passados, percebemos uma grande diferença. Os canteiros exuberantes com flores variadas não mais existem. Remanescentes dessa época, apenas a vegetação maior, composta por arbustos, palmeiras e árvores de grande porte. De todo aquele esplendor que essas áreas possuíam no século XIX e XX, pouco sobrou, resta apenas o traçado, os chafarizes e Caixa d'Água. Claro que essas praças e parques foram vítimas do tempo, mas também do descaso da população e do poder público. Cabe lembrar também que o esplendor das áreas verdes em séculos passados era financiado por ricos charqueadores, hoje não mais presentes.

Quando analisada a legislação municipal, principalmente das duas últimas décadas, percebe-se que está previsto em muitas leis a responsabilidade do poder público e da coletividade sobre a manutenção, conservação e expansão das áreas verdes. No último Plano Diretor do município (2008), está estabelecido que todo uso comercial fixo nas áreas verdes é proibido, entretanto não é o que ocorre no Parque Linear Bairro Fragata, devido a presença de 16 floriculturas.

Com relação a instalação de brinquedos adaptados para crianças com deficiência ou mobilidade reduzida, até o momento da pesquisa nenhuma área verde objeto de estudo contava com tal equipamento.

\section{Referências}

Cunha, R.D.A. (2003) Os espaços públicos abertos e as leis de uso e ocupação do solo: uma questão de qualidade para ambientes sustentáveis. Em: III Encontro Nacional sobre
Edificações e Comunidades Sustentáveis: "Produção e Gestão do Ambiente Construído Sustentável".

Lima, A.M.L.P.; Cavalheiro, F.; Nucci, J.C.; Souza, M.A. de L.B.; Fialho, N. de O.; Del Picchia, P.C.D. (1994). Problemas de utilização na conceituação de termos como espaços livres, áreas verdes e correlatos. Em: II Congresso Brasileiro de Arborização Urbana.

Nucci, J.C. (2008). Qualidade Ambiental e Adensamento Urbano: um estudo de ecologia e planejamento da paisagem aplicado ao distrito de Santa Cecília (MSP).

Oliveira, E.P. (2007). Viagem na Memória do Fragata: estudo sobre a história e cultura de um "bairro cidade".

Paradeda, M.R. (2003). Arquitetura da Paisagem e Modernidade: um estudo sobre representações e memória das Praças de Pelotas (1860-1930).

Peter, G.D. (2004). Santa Bárbara: o braço morto do arroio que ainda vive na memória.

Silva, G.P.; Versiani, I.V.L. (2011). Brasil: Espaço público de lazer no ambiente urbano: ampliação das possibilidades de convivência, socialização e mudança de cenários violentos. Desarrollo Humano. Boletim, 74.

Xavier, J.S. (2006). Chafarizes e caixa d'água de Pelotas: elementos de modernidade do primeiro sistema de abastecimento (1871).

\section{Leis}

PELOTAS. Lei n. 1.672/1968. Aprova o Plano Diretor e suas diretrizes gerais e dá outras providências. Disponível em: http://www.pelotas.rs.gov.br/

PELOTAS. Lei n. 2.565/1980. Institui o II Plano Diretor de Pelotas. Disponível em: http://www.pelotas.rs.gov.br/

PELOTAS. Lei n. 3.174/1980. Altera as disposições da lei 2565/80 que institui o II plano diretor de Pelotas e dá outras providências. Disponível em: http://www. pelotas.rs.gov.br/

PELOTAS. Lei n. 4.125/1996. Dispõe sobre a criação do "Programa Adote uma Área Verde" e dá outras providências. Disponível em: http://www.pelotas.rs.gov.br/

PELOTAS. Lei n. 4.146/1996. Acrescenta parágrafo no art. 13, da Lei Municipal no 4125/96 que dispõe sobre o Programa de Adoção de Áreas Verdes e suprime seu inciso. Disponível em: http://www.pelotas.rs.gov.br/

PELOTAS. Lei n. 4.147/1996. Acrescenta parágrafos no art. $2^{\circ}$, da Lei Municipal n⿳ำ 4125/96, que dispõe sobre o 
Programa de Adoção de Áreas Verdes. Disponível em: http://www.pelotas.rs.gov.br/

PELOTAS. Lei n. 4.594/2000. Institui o Código do Meio Ambiente do Município de Pelotas, e dá outras providências. Disponível em: http://www.pelotas.rs.gov. br/

PELOTAS. Lei n. 4.724/2001. Dispõe sobre o Programa Adote uma Área Verde, revogando as Leis no 4.125/96, 4.146/96 e 4.147/96, e dá outras providências. Disponível em: http://www.pelotas.rs.gov.br/

PELOTAS. Lei n. 5.502/2008. Institui o Plano Diretor Municipal e estabelece as diretrizes e proposições de ordenamento e desenvolvimento territorial no município de Pelotas, e dá outras providências. Disponível em: http://www.pelotas.rs.gov.br/

PELOTAS. Lei n. 5.880/2012. Dispõe sobre a Criação da Campanha Ordinária de Incentivo a Arborização de Ruas, Praças e Jardins do Município de Pelotas. Disponível em: http://www.pelotas.rs.gov.br/

PELOTAS. Lei n. 5.910/2012. Institui o Prêmio Primavera a ser conferido aos munícipes, entidades do setor público ou privado, que participem ou tenham se destacado na manutenção e conservação de canteiros, praças e rotatórias e dá outras providências. Disponível em: http://www.pelotas.rs.gov.br/

PELOTAS. Lei n. 6.116/2014. Determina a instalação, nas áreas públicas destinadas ao lazer ou à recreação no Município de Pelotas, de no mínimo, 01 (um) brinquedo adaptado para lazer e recreação infantil, adaptado para crianças com deficiência física ou com mobilidade reduzida, e dá outras providências. Disponível em: http://www.pelotas.rs.gov.br/

PELOTAS. Agenda 21 de Pelotas: construindo a cidadania ambiental. Pelotas: SQA/PMPel, 2004.

\section{Sites}

MINISTÉRIO DO MEIO AMBIENTE. Parques e Áreas Verdes. Disponível em: http://www.mma.gov.br/.

PREFEITURA MUNICIPAL DE PELOTAS. Legislação. Disponível em: http://www.pelotas.rs.gov.br/ 